\title{
Pigment epithelial pattern dystrophy: a peripheral type
}

\section{J WILLEM DELLEMAN' AND PAUL $T$ V M DE JONG}

From the 'Department of Ophthalmogenetics, The Netherlands Ophthalmic Research Institute, Amsterdam, The Netherlands, and the 'Department of Ophthalmology, Erasmus University, Eye Hospital, Rotterdam, The Netherlands

SUMMARY A hitherto undescribed form of pattern dystrophy of the retinal pigment epithelium was found in a patient suffering from mucopolysaccharidosis II or Hunter's disease. We propose the name peripheral pattern dystrophy.

The pattern dystrophies of the retina are characterised by pigmented, non-elevated changes in the retinal pigment epithelium (RPE) that block background fluorescence at all stages of the fluorescein angiogram. As a rule they are inherited in an autosomal dominant way. A slightly reduced visual acuity has sometimes been mentioned, but a reduced electro-oculogram (EOG) is one of the only consistent findings. Among the pattern dystrophies are reticular dystrophy, fundus pulverulentus, butterfly dystrophy, macroreticular dystrophy, and horseshoe dystrophy. 'Up till now no relation between a pattern dystrophy and a generalised disorder has been described.

Here we report a hitherto unpublished type of RPE dystrophy in a patient with biochemically proved mucopolysaccharidosis (MPS) II, or Hunter's disease, for which we suggest the name peripheral pattern dystrophy.

\section{Case history}

The proband, born in 1965 at term after a normal pregnancy, was the fourth son of nonconsanguineous parents (Fig. 1). There were no perinatal problems. His eldest brother had MPS II, but otherwise there were no abnormalities in the family. At the age of 7 it became clear that the proband was also afflicted by MPS II. His mental

Correspondence to Paul T V M de Jong, MD, Eye Hospital, Schiedamsevest 180, $3011 \mathrm{BH}$ Rotterdam, The Netherlands. development was normal. In 1979 an iduronide-2sulphate-sulphatase deficiency was demonstrated in

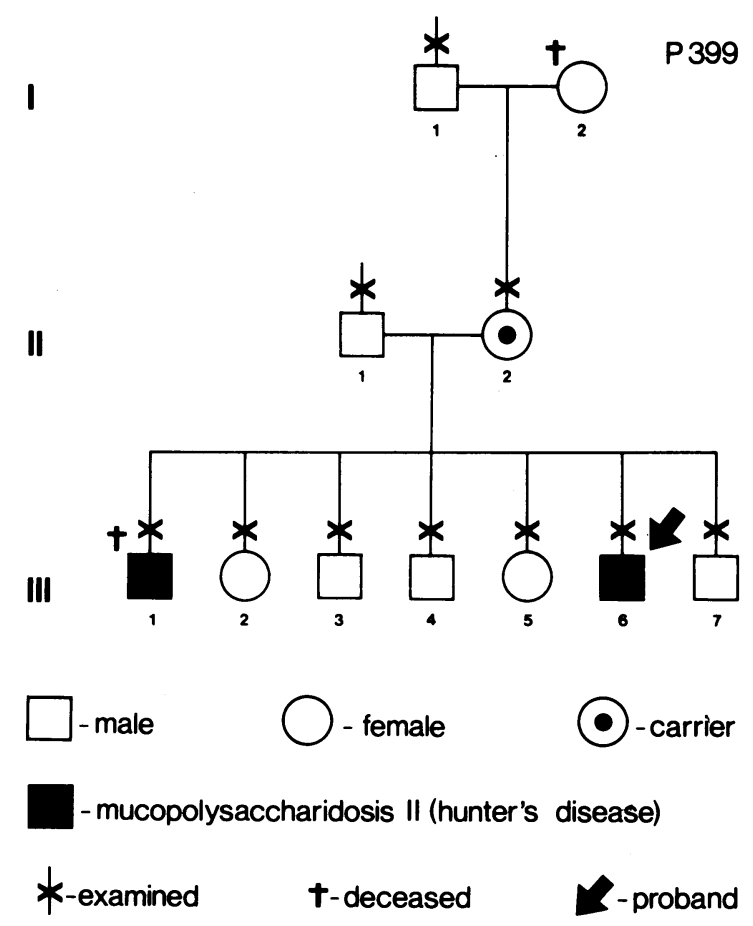

Fig. 1 Pedigree of the proband's family. 


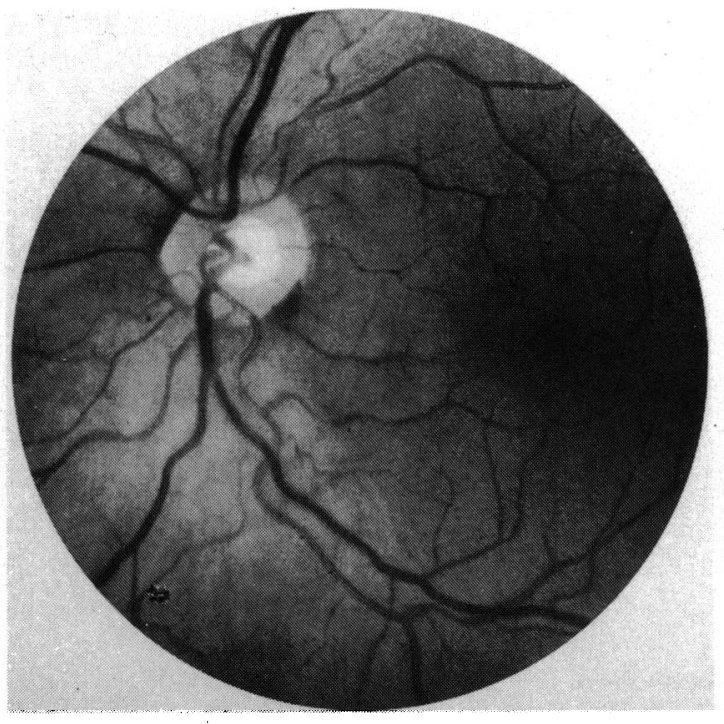

Fig. 2 Fundus picture of proband's left eye in 1979. Note fine radial folds around the fovea.

skin fibroblast cultures of the proband and his brother, indicating MPS II.

The first eye examination was performed in 1978 . Both eyes had a visual acuity of $6 / 6$ and a refraction of $+1 \cdot 00$. There were no corneal opacities. On funduscopy there was a normal macular reflex. At the periphery no abnormalities were found.

In 1979, however, for the first time fine radial retinal folds were noted as well as slightly blurred disc margins (Fig. 2). Thereafter the patient visited the outpatient department every six to eight months. Extensive pigmented lines all around the periphery of the right eye (Figs. 3,4) became visible for the first time in 1980. These lines, parallel to the limbus, located at the equator, had radial extensions towards the ora serrata. Gradually they became more and more pigmented, and a fine pigment clump appeared exactly in the centre of the fovea. At the end of 1983 vague pigmented lines became visible for the first time in the left eye. In July $1984 \mathrm{~V}$-shaped pigmented lines were present at 9 and 11 o'clock in the periphery of the left eye similar to those at 3 o'clock in the right eye (Figs. 3, 4). On Goldmann perimetry a slightly enlarged blind spot was found. The final threshold of rod dark adaptation was raised by 1.5 to $3 \log$ units (Goldmann-Weekers), while the light rise response was within normal limits. Ganzfeld light flash stimulation revealed normal rod and cone mediated a and $b$ waves in the electroretinogram (ERG) with lowered oscillatory potentials. The ERG, evoked with a $1^{\circ}$ and $80 \%$ contrast check reversal move- ment, was also normal, whereas the visually evoked potentials (VEPs) to the same stimulus showed normal amplitudes and slightly prolonged latencies in the right eye and clearly lowered and delayed responses in the left eye. Most of the methods used have been described. ${ }^{2}$ Examination of the living family member of the proband (Fig. 1) showed no pigment epithelial changes.

The elder brother of the proband with MPS II died of tracheomalacia. His eyes were slightly autolytic at histological examination. No pigment epithelial abnormalities could be found, however.

\section{Discussion}

In some cases of MPS II pigment epithelial changes have been described, but nearly always resembling a tapetoretinal dystrophy. ${ }^{37}$ In most reports on MPS, however, there has been no mention of any biochemical means of detecting the enzyme defect. Thus it is possible that different types of MPS have been wrongly classified under one heading. On the other hand many patients have been described with no pigmentary abnormalities. We have personally examined four more patients with biochemically proved MPS II but without pigment epithelial abnormalities. We classify the linear, non-elevated, pigmented lines of the proband that blocked fluorescence during the angiogram as a new type of pattern RPE dystrophy. The lines show some resemblance to macroreticular dystrophy, but this dystrophy has so far been described only in the posterior pole. ${ }^{\mathrm{9}}$

We have seen these lines, much less extensively developed, only in patients with longstanding choroidal or retinal detachments. In the retinal detachment cases the high-tide marks probably represent linear reactive hyperplasia of the pigment epithelium. In our patient no retinal or choroidal detachment or uveal effusion has been seen, though he has had an ophthalmic check-up every six to eight months since 1979. Nor could any sign of vitreous traction bands be found on biomicroscopy. Patients with peripheral drusen often have a reticular pattern dystrophy of the RPE, but our patient had no drusen. The absence of any of these signs in the left eye at the time that the pigmented lines are developing also points to a genuine pigment epithelium dystrophy. The radial retinal folds in the posterior pole show a resemblance to those found in $\mathrm{X}$-linked juvenile retinoschisis, but in our proband no schisis could be found, even though indentation biomicroscopy was performed. His visual acuity was also not consistent with such a diagnosis. We have previously discussed pattern dystrophies more fully.'

The eyes of the elder brother, who died because of tracheomalacia, were obtained for histological study. 


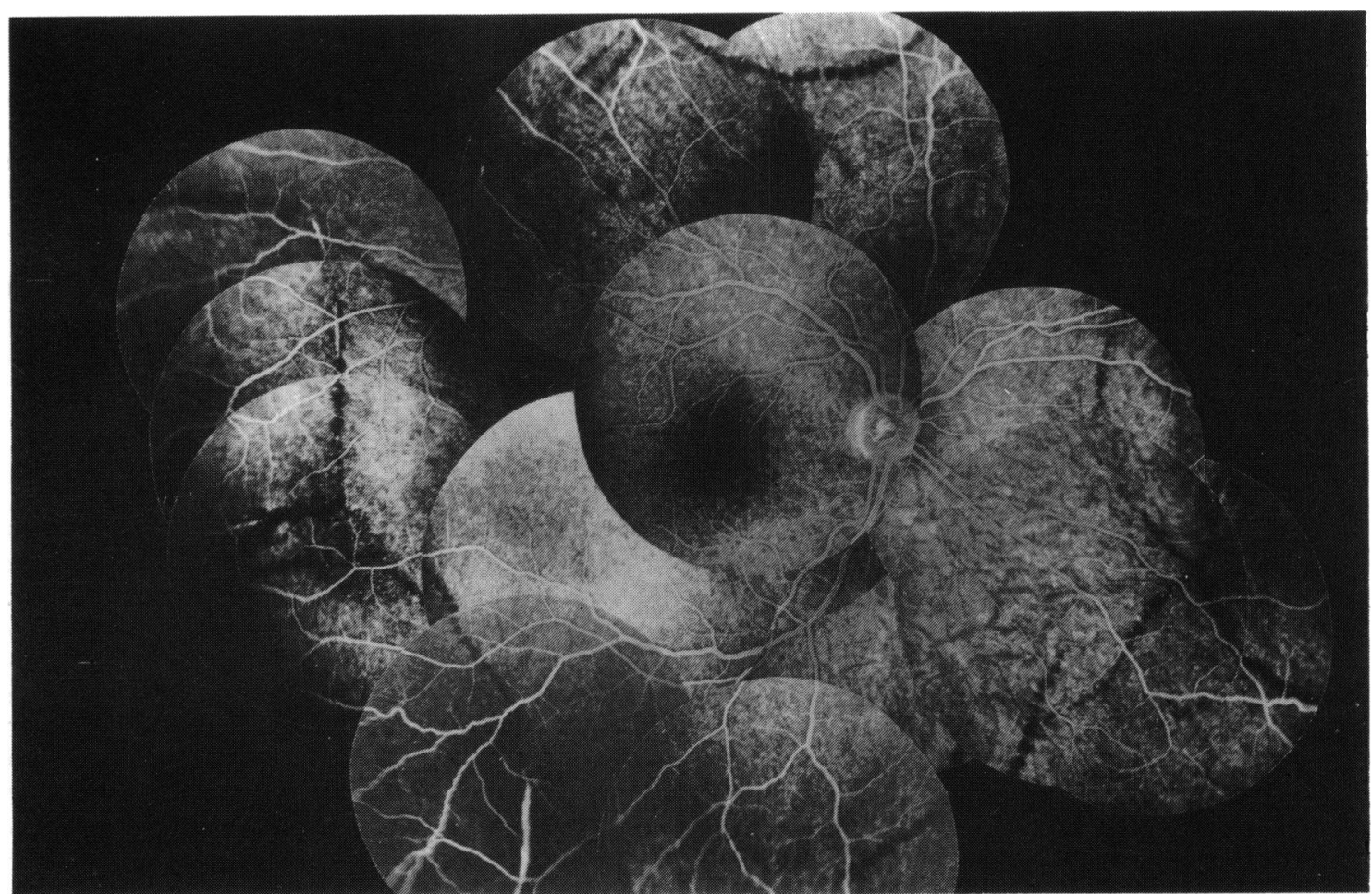

Fig. 3 Composite fundus picture of the right eye of proband in 1982. Late arteriovenous phase of fluorescein angiogram. Note peripheral pigmented lines. Because of deep set eyes the far periphery could not be photographed.

Fig. 4 Schematic drawing of pigmented lines in the same eye as seen by indirect ophthalmoscopy.

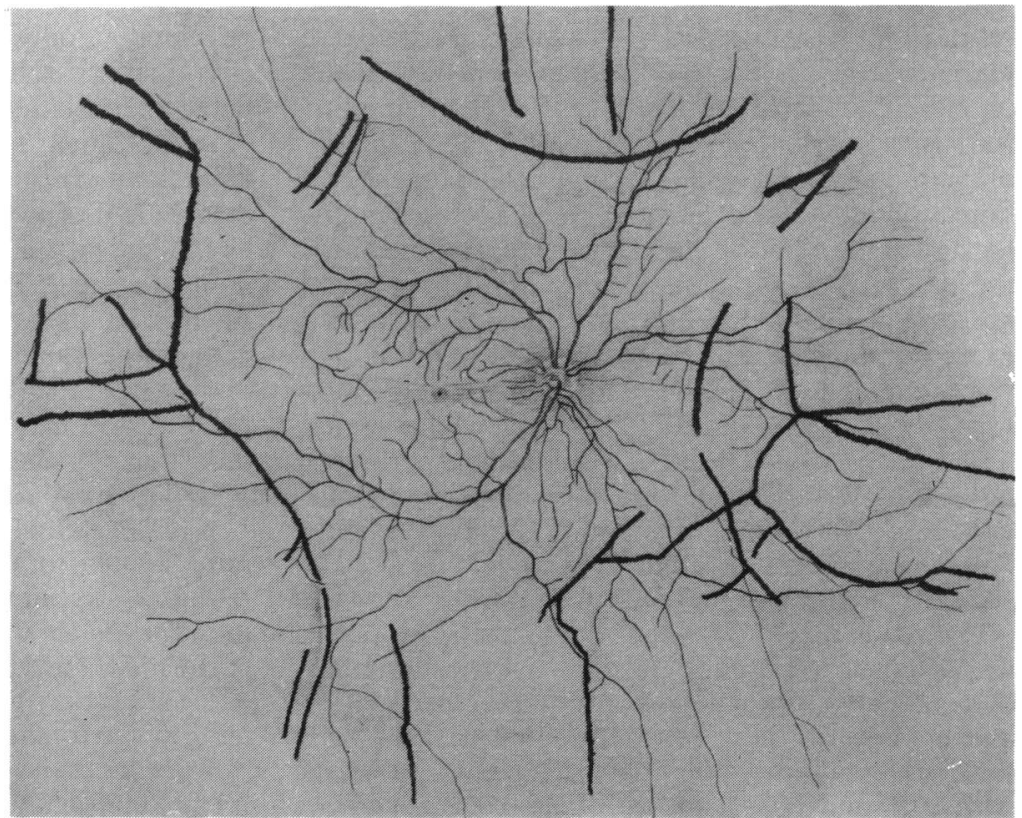


Although they were slightly autolytic, no pigment abnormalities were seen.

There are findings that do not exactly fit in with the diagnosis of pattern dystrophy of the RPE. Although the standing potential of the EOG was low, there was still a good light rise. Moreover the dark adaptation curve and the delayed latencies on testing the VEP were abnormal. The VEP abnormalities, however, have been mentioned more often in patients with MPS II" and probably are due to accumulation of mucopolysaccharides in the optic nerve, resulting in blurred discs.

We have found no reports of pattern dystrophies in patients with MPS II. Moreover the four patients we have examined had no pigmentation in the periphery. It may be possible that in some of these patients, who are sometimes difficult to examine, pigmentations in the fundus periphery have been overlooked. On the other hand we believe that up till now there is insufficient support for the suggestion that the fundus pigmentation in our proband with MPS II is more than a coincidental finding.

We would like to thank C B Schotel and T Put for their art work and Mrs C H M Muijlwijk-Planting and Mrs M A T BoothHoppenbrouwers for their secretarial help.
References

1 De Jong PTVM, Delleman JW. Pigment epithelial pattern dystrophy. Four different manifestations in a family. Arch Ophthalmol 1982; 100: 1416-21.

2 Van Lith GHM. In: Michaelson IC. Textbook of the fundus of the eye. 3rd ed. Edinburgh: Churchill Livingstone, 1980: 23-41, 627-54.

3 Hooper JMD. An unusual case of gargoylism. Guy's Hosp Rep 1952; 101: 222-8.

4 Gills JP, Hobson R, Hanley B, McKusick VA. Electroretinography and fundus oculi findings in Hurler's disease and allied mucopolysaccharidoses. Arch Ophthalmol 1965; 74: 596-603.

5 Goldberg MF, Duke JR. Ocular histopathology in Hunter's syndrome. Systemic mucopolysaccharidosis type II. Arch Ophthalmol 1967; 77: 503-12.

6 Thomas Ch, Raspiller A, Fall M. Les atteintes cornéennes et rétiniennes au cours des mucopolysaccharidoses (à propos de huit observations). Bull Soc Ophtalmol Fr 1970; 70: 933-41.

7 Leung LSE, Weinstein GW, Hobson RR. Further electroretinographic studies of patients with mucopolysaccharidoses. Birth Defects Orig Art Ser 1971; 7/3: 32-40.

8 Mesker RP, Oosterhuis JA, Delleman JW. A retinal lesion resembling Sjögren's dystrophia reticularis laminae pigmentosae retinae. In: Winkelman JE, Crone RA, eds. Perspectives in ophthalmology. Amsterdam: Excerpta Medica, 1970: 2: 40-5.

9 Girard P, Setbon G, Forest A, Coscas G. Dystrophies en réseau de l'épithélium pigmentaire (dystrophies macroréticulaires et en ailc de papillon). J Fr Ophtalmol 1980; 3: 101-8.

10 Abraham FA, Yatziv S, Russell A, Aucrbach E. Electrophysiological and psychophysical findings in Hunter syndrome. Arch Ophthalmol 1974; 91: 181-6. 